$\mathbb{T}$ periodica polytechnica

Electrical Engineering and Computer Science

$56 / 2(2012) 35,41$

doi: 10.3311/PPee.7076

http://periodicapolytechnica.org/ee

Creative Commons Attribution (i)

RESEARCH ARTICLE

\section{Integral calculus usage for conductor length determination on the basis of known maximal sag of a parabola}

\author{
Alen Hatibovic
}

Received 2012-01-25, accepted 2012-02-24

\begin{abstract}
This paper shows a mathematic solution for calculation of conductor length using integral calculus on a parabola. The presented method can be used for spans approximately up to 400 metres. In that case the catenary may be approximated by a parabola (quadratic function), while the difference between the catenary and the parabola is negligible. The necessary data are the span length, the heights of the suspension points and the value of the maximal sag. The algorithm is prepared for inclined spans, but it is applicable for levelled spans too, because it is just one special case when the conductor suspension points on two supports are on the same height level. Naturally, the conductor length changes with temperature, so it is possible to calculate it for a chosen temperature, using a conductor sag for that temperature, chosen tension and conductor type.
\end{abstract}

\section{Keywords}

parabola $\cdot$ catenary $\cdot$ span $\cdot$ sag $\cdot$ conductor length $\cdot$ equation

\section{Acknowledgement}

The author would like to express his thank to EDF DÉMÁSZ, especially to its branches Prímavill Kft. and DHE Kft. where he has been working 15 years up to now as a designer engineer than as a senior engineer for electric network development. Having opportunity to plan and design kilometres of overhead lines and underground cables and gaining a lot of expirience, the author could also provide many new methods and calculations and then to check them in practice. As a result of that work the author has written 15 scientific publications and has shown them on respectable professional conferences and in scientific journals both in Hungary and abroad.

This paper presents the part of EDF DHE Kft. project called Designer Programme, which entered the 19th Hungarian Innovation Award Competition. The Designer Programme as a recognised innovation got into the Innovation Award 2010 book under number 12.

\section{Alen Hatibovic}

EDF DÉMÁSZ Hálózati Elosztó Kft, H-6720 Szeged, Hungary

e-mail: hatibovic.alen@gmail.com

\section{Introduction}

To calculate the conductor length (in our case the parabola length) we have to define the equation for the conductor height. In the presented method the origin of the coordinate system is put at the bottom of the left-hand side support of the span, so the conductor height at any point of the span is related to $x$-axis. It makes the usage of the presented method easy and natural in real work. Knowing the equation for the conductor height, it is possible to calculate the conductor length. Generally, in scientific literature only the method for levelled spans [1] can be found, on the basis of the known span length and the maximal sag.

$$
L=a+\frac{8}{3} \cdot \frac{b_{\max }^{2}}{a}
$$

For inclined spans a new algorithm is needed based on the integral calculus, which is shown in this paper. The final algorithm is useful both for the levelled and the inclined spans as well. Moreover, it makes possible to calculate the conductor length of any part of the span making the algorithm universal.

Generally, the arc length of the curve $y=f(x)$ over $\left[x_{1}, x_{2}\right]$, is defined by the following formula [2]:

$$
L_{x_{1}, x_{2}}=\int_{x_{1}}^{x_{2}} \sqrt{1+\left(f^{\prime}(x)\right)^{2}} d x
$$

So the conductor length within the whole span is the length of the parabola over the interval $[0, a]$, according to the following formula:

$$
L=\int_{0}^{a} \sqrt{1+\left(f^{\prime}(x)\right)^{2}} d x
$$

It is obvious that the calculation would be long and very complicated by using the standard form of the parabola equation. To reduce the calculation, it is recommended to replace the parabola curve at $x-y$ coordinate system, so that the vertex (MIN point) of the parabola should be in the origin [3]. At first, it is necessary to transform the standard equation of the parabola to its vertex form. By that way the coordinates of the vertex of the parabola shall also be defined. After that it is easy to replace the parabola in the coordinate system and change appropriately the integral limits for length calculation. 
Fig. 1. Inclined span

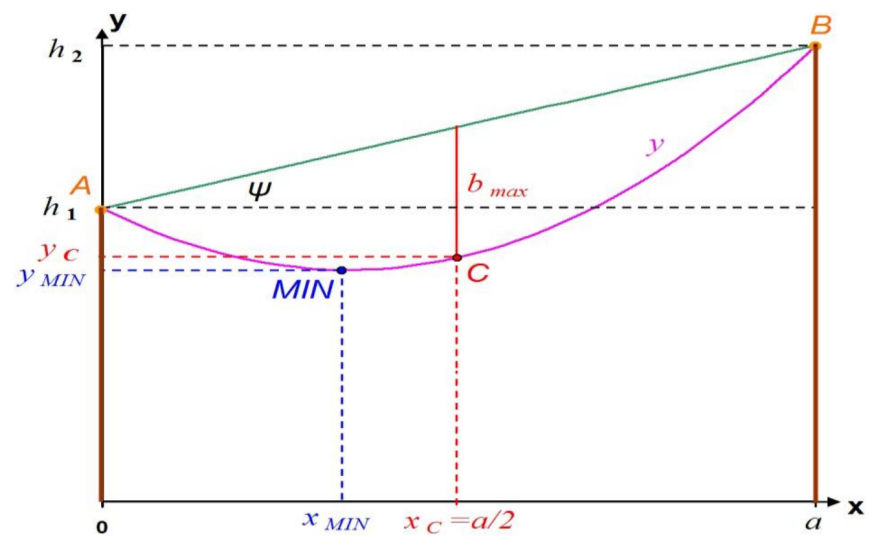

$a-$ span length
$h_{1}-$ height of the left-
hand side suspension
point
$h_{2}$ - height of the right-
hand side suspension
point
$b_{\max }$ - maximal sag
$M I N$ - the lowest point
$\psi-$ angle
$y-$ conductor curve

\section{Equation for the conductor height}

At first, the equation for the conductor height has to be defined [4]. It is solved on the basis of the three known points of the conductor curve, because the parabola is completely defined when any three points of its curve are known. The suspension points of the span are always known points, while the third necessary point is defined by the known maximal sag.

In mathematic literature the parabola of the conductor is known as a regular (vertical) parabola. The general form of the equation of the parabola is the following:

$$
y=A x^{2}+B x+C
$$

Two suspension points are $A\left(0 ; h_{1}\right)$ and $B\left(a ; h_{2}\right)$. In the case of the parabola the maximal sag is always located in the mid-span, $x_{c}=a / 2$, which defines the third point $C\left(x_{c} ; y_{c}\right)$.

$$
\begin{aligned}
y_{C}=h_{1}+\frac{h_{2}-h_{1}}{2}-b_{\max } & \\
& =\frac{2 h_{1}}{2}+\frac{h_{2}}{2}-\frac{h_{1}}{2}-b_{\max }=\frac{h_{1}+h_{2}}{2}-b_{\max }
\end{aligned}
$$

So the third point of the parabola is determined:

$$
C\left(\frac{a}{2} ; \frac{h_{1}+h_{2}}{2}-b_{\max }\right)
$$

Let us write the system of three equations with three unknown variables using the general form of the equation of the parabola (4) :

$$
\begin{aligned}
h_{1} & =C \\
h_{2} & =A a^{2}+B a+C \\
\frac{h_{1}+h_{2}}{2}-b_{\max } & =A\left(\frac{a}{2}\right)^{2}+B\left(\frac{a}{2}\right)+C
\end{aligned}
$$

The system can be written and solved in the following way :

$$
\begin{gathered}
{\left[\begin{array}{ccc}
0 & 0 & 1 \\
a^{2} & a & 1 \\
(a / 2)^{2} & a / 2 & 1
\end{array}\right] \cdot\left[\begin{array}{l}
A \\
B \\
C
\end{array}\right]=\left[\begin{array}{c}
h_{1} \\
h_{2} \\
\left(h_{1}+h_{2}\right) / 2-b_{\max }
\end{array}\right]} \\
{\left[\begin{array}{l}
A \\
B \\
C
\end{array}\right]=\left[\begin{array}{c}
4 b_{\max } / a^{2} \\
\left(h_{2}-h_{1}-4 b_{\max }\right) / a \\
h_{1}
\end{array}\right]}
\end{gathered}
$$

So we have the $A, B, C$ coefficients of the parabola:

$$
\begin{gathered}
A=\frac{4 b_{\max }}{a^{2}} \\
B=\frac{h_{2}-h_{1}-4 b_{\max }}{a} \\
C=h_{1}
\end{gathered}
$$

Substituting these into (4), the equation for the conductor height is completely obtained:

$$
y=\frac{4 b_{\max }}{a^{2}} x^{2}+\frac{h_{2}-h_{1}-4 b_{\max }}{a} x+h_{1}, \quad x \in[0, a]
$$

This is a standard equation form of the parabola. Let us emphasize that the defined equation is universal, since it is valid both for levelled $\left(h_{1}=h_{2}\right)$ and inclined $\left(h_{1}<h_{2}\right.$ or $\left.h_{1}>h_{2}\right)$ spans, despite the fact that the inclined span has two types. Of course, in each case the appropriate value of the maximal sag has to be used, which has to be obtained by some programme for sag calculation, or taken from sag-tension tables, because the determination of the maximal sag is not the task of this paper.

\section{Vertex form of the parabola}

In order to reduce the calculation the parabola curve has to be replaced in $x-y$ coordinate system, so that the vertex (MIN point) of the parabola should be in the origin. At first, it is necessary to transform the standard equation of the parabola (4) to its vertex form 16 :

$$
y=A\left(x-x_{\mathrm{MIN}}\right)^{2}+y_{\mathrm{MIN}}
$$

The way of the parabola equation transformation is shown in the following lines:

$$
\begin{aligned}
y & =\frac{4 b_{\max }}{a^{2}} x^{2}+\frac{h_{2}-h_{1}-4 b_{\max }}{a} x+h_{1} \\
& =\frac{4 b_{\max }}{a^{2}}\left(x^{2}+\frac{a^{2}}{4 b_{\max }} \cdot \frac{h_{2}-h_{1}-4 b_{\max }}{a} x\right)+h_{1} \\
& =\frac{4 b_{\max }}{a^{2}}\left[x^{2}+a\left(\frac{h_{2}-h_{1}}{4 b_{\max }}-1\right) x\right]+h_{1}
\end{aligned}
$$




$$
\begin{aligned}
y= & \frac{4 b_{\max }}{a^{2}}\left\{x^{2}-a\left(1-\frac{h_{2}-h_{1}}{4 b_{\max }}\right) x+\right. \\
& \left.+\left[\frac{a}{2} \cdot\left(1-\frac{h_{2}-h_{1}}{4 b_{\max }}\right)\right]^{2}\right\} \\
& +h_{1}-\frac{4 b_{\max }}{a^{2}}\left[\frac{a}{2}\left(1-\frac{h_{2}-h_{1}}{4 b_{\max }}\right)\right]^{2} \\
= & \frac{4 b_{\max }}{a^{2}}\left[x-\frac{a}{2}\left(1-\frac{h_{2}-h_{1}}{4 b_{\max }}\right)\right]^{2} \\
& +h_{1}-b_{\max }\left(1-\frac{h_{2}-h_{1}}{4 b_{\max }}\right)^{2}, \quad x \in[0, a]
\end{aligned}
$$

Equation (17) is the vertex form equation of the parabola. It is completely equal with equation (15), but more applicable for the parabola replacement and integral calculus.

$$
\begin{gathered}
A=\frac{4 b_{\max }}{a^{2}} \\
x_{\mathrm{MIN}}=\frac{a}{2}\left(1-\frac{h_{2}-h_{1}}{4 b_{\max }}\right) \\
y_{\mathrm{MIN}}=h_{1}-b_{\max }\left(1-\frac{h_{2}-h_{1}}{4 b_{\max }}\right)^{2}
\end{gathered}
$$

$x_{\mathrm{MIN}}$ and $y_{\mathrm{MIN}}$ are the coordinates of the vertex. Since $A>0$, $y_{\mathrm{MIN}}=f\left(x_{\mathrm{MIN}}\right)$ is the minimum [5] of parabola. In Figure 1 the vertex (MIN point) is the lowest point of the conductor [6]. Parabola curve with vertex being replaced into origin has the following equation:

$$
y=\frac{4 b_{\max }}{a^{2}} x^{2}, \quad x \in\left[-x_{\mathrm{MIN}}, a-x_{\mathrm{MIN}}\right]
$$

The parabola equation (21) is much more applicable than the equation 15 for the length integral according to (3). The parabola replacement will not result a change in its length in the case of the appropriate change of the interval, from $[0, a]$ to $\left[-x_{\mathrm{MIN}}, a-x_{\mathrm{MIN}}\right]$.

\section{Conductor length}

The length of the parabola 21] over the interval [ $-x_{\mathrm{MIN}}, a-$ $\left.x_{\mathrm{MIN}}\right]$ is given by the following formula:

$$
L=\int_{-x_{\mathrm{MIN}}}^{a-x_{\mathrm{MIN}}} \sqrt{1+\left(y^{\prime}\right)^{2}} d x
$$

Using the basic derivation rule $\left(a x^{n}\right)^{\prime}=n \cdot a \cdot x^{n-1}$ the first derivative of 21] is:

$$
y^{\prime}=2 \cdot \frac{4 b_{\max }}{a^{2}} x=\frac{8 b_{\max }}{a^{2}} x
$$

Squaring (23) results in:

$$
\left(y^{\prime}\right)^{2}=\left(\frac{8 b_{\text {max }}}{a^{2}}\right)^{2} x^{2}=A_{1}^{2} x^{2}
$$

To compute easily the integral we use the substitution method:

$$
\begin{aligned}
A_{1} x & =\sinh (t) \\
A_{1} d x & =\cosh (t) \cdot d t \\
d x & =\frac{1}{A_{1}} \cosh (t) \cdot d t
\end{aligned}
$$

Substituting 25) and 27) into 22) and evaluating the integral

$$
\begin{aligned}
& L=\int_{-x_{\mathrm{MIN}}}^{a-x_{\mathrm{MIN}}} \sqrt{1+A_{1}^{2} x^{2}} d x \\
& =\int_{t_{1}}^{t_{2}} \sqrt{1+\sinh ^{2} t} \frac{1}{A_{1}} \cosh (t) \cdot d t \\
& =\int_{t_{1}}^{t_{2}} \cosh (t) \cdot \frac{1}{A_{1}} \cosh (t) \cdot d t \\
& =\frac{1}{A_{1}} \int_{t_{1}}^{t_{2}} \cosh ^{2}(t) \cdot d t=\left.\frac{1}{A_{1}} \cdot \frac{1}{2}\left(t+\frac{\sinh 2 t}{2}\right)\right|_{t_{1}} ^{t_{2}} \\
& =\left.\frac{1}{2 A_{1}}\left(t+\frac{1}{2} \cdot 2 \sinh t \cdot \cosh t\right)\right|_{t_{1}} ^{t_{2}} \\
& =\left.\frac{1}{2 A_{1}}\left(t+\sinh t \cdot \sqrt{1+\sinh ^{2} t}\right)\right|_{t_{1}} ^{t_{2}} \\
& =\left.\frac{1}{2 A_{1}}\left[\operatorname{arsinh}\left(A_{1} x\right)+A_{1} x \sqrt{1+A_{1}^{2} x^{2}}\right]\right|_{-x_{\mathrm{MIN}}} ^{a-x_{\mathrm{MIN}}} \\
& =\left.\frac{1}{2} \frac{a^{2}}{8 b_{\max }}\left[\operatorname{arsinh} \frac{8 b_{\max }}{a^{2}} x+\frac{8 b_{\max }}{a^{2}} x \sqrt{1+\left(\frac{8 b_{\max }}{a^{2}}\right)^{2} x^{2}}\right]\right|_{-x_{\mathrm{MIN}}} ^{a-x_{\mathrm{MIN}}} \\
& =\frac{a^{2}}{16 b_{\max }}\left[\operatorname{arsinh} \frac{8 b_{\max }}{a^{2}}\left(a-x_{\mathrm{MIN}}\right)+\operatorname{arsinh} \frac{8 b_{\max }}{a^{2}} x_{\mathrm{MIN}}\right. \\
& +\frac{8 b_{\mathrm{max}}}{a^{2}}\left(a-x_{\mathrm{MIN}}\right) \sqrt{1+\left(\frac{8 b_{\mathrm{max}}}{a^{2}}\right)^{2}\left(a-x_{\mathrm{MIN}}\right)^{2}} \\
& +\frac{8 b_{\max }}{a^{2}} x_{\mathrm{MIN}} \sqrt{1+\left(\frac{8 b_{\max }}{a^{2}} x_{\mathrm{MIN}}\right)^{2}}
\end{aligned}
$$

Equation (28) is the final formula for the conductor length within the whole span.

\section{Conductor length of any part of the span}

Integral calculus gives us an opportunity to determine not only the conductor length within the whole span, but also the conductor length at any part of the span, $L_{x_{1} x_{2}}$ over the interval $\left[x_{1}, x_{2}\right]$. In this case the appropriate calculation is the following:

$$
\begin{aligned}
L_{x_{1} x_{2}}= & \int_{x_{1}-x_{\mathrm{MIN}}}^{x_{2}-x_{\mathrm{MIN}}} \sqrt{1+\left(y^{\prime}\right)^{2}} d x \\
= & \frac{a^{2}}{16 b_{\max }}\left[\operatorname{arsinh} \frac{8 b_{\mathrm{max}}}{a^{2}}\left(x_{2}-x_{\mathrm{MIN}}\right)-\operatorname{arsinh} \frac{8 b_{\mathrm{max}}}{a^{2}}\left(x_{1}-x_{\mathrm{MIN}}\right)\right. \\
& +\frac{8 b_{\max }}{a^{2}}\left(x_{2}-x_{\mathrm{MIN}}\right) \sqrt{1+\left(\frac{8 b_{\mathrm{max}}}{a^{2}}\right)^{2}\left(x_{2}-x_{\mathrm{MIN}}\right)^{2}} \\
& \left.-\frac{8 b_{\max }}{a^{2}}\left(x_{1}-x_{\mathrm{MIN}}\right) \sqrt{1+\left(\frac{8 b_{\mathrm{max}}}{a^{2}}\right)^{2}\left(x_{1}-x_{\mathrm{MIN}}\right)^{2}}\right]
\end{aligned}
$$

The last formula is quite universal for the parabola. The calculation of the conductor length of the span part is not a usual task, but the formula 29) is a basic, important one. For instance in the case of the following integral limits $x_{1}=0$ and $x_{2}=a$, the result is the conductor length within the whole span, a very common task. Furthermore, the 29] formula solves the levelled span, too. For that case 29] will be transformed into a significantly simpler formula. 
Fig. 2. Example 1 - Determination of the conductor length within the levelled span

\begin{tabular}{|c|c|c|}
\hline \multicolumn{3}{|c|}{ INPUT DATA } \\
\hline SPAN LENGTH & $a[\mathrm{~m}]$ & 400,00 \\
\hline $\begin{array}{c}\text { LETT-HAND SUSPENSION } \\
\text { POINT HEIGHT }\end{array}$ & $\mathrm{h}_{1}[\mathrm{~m}]$ & 20,50 \\
\hline $\begin{array}{c}\text { RIGHT-HAND SUSPENSION } \\
\text { POINT HEIGHT }\end{array}$ & $\mathrm{h}_{2}[\mathrm{~m}]$ & 20,50 \\
\hline MAXIMAL SAG & $\mathrm{b}_{\max }[\mathrm{m}]$ & 12,70 \\
\hline
\end{tabular}

\begin{tabular}{|c|c|c|c|}
\hline \multicolumn{2}{|c|}{ VERTEX OF PARABOLA } & \multirow{2}{*}{\multicolumn{2}{|c|}{$\begin{array}{l}\text { COEFFICIENT } \\
\text { OF PARABOLA }\end{array}$}} \\
\hline $\mathrm{x}_{\mathrm{MIN}}[\mathrm{m}]$ & 200,000 & & \\
\hline $\mathrm{Y}_{\mathrm{MIN}}[\mathrm{m}]$ & 7,800 & A & 0,0003175 \\
\hline
\end{tabular}

PARABOLA EQUATION : $\quad \mathrm{y}=\mathrm{A}\left(\mathrm{x}-\mathrm{x}_{\mathrm{MIN}}\right)^{2}+\mathrm{y}_{\mathrm{MIN}}$

- VERTEX OF PARABOLA

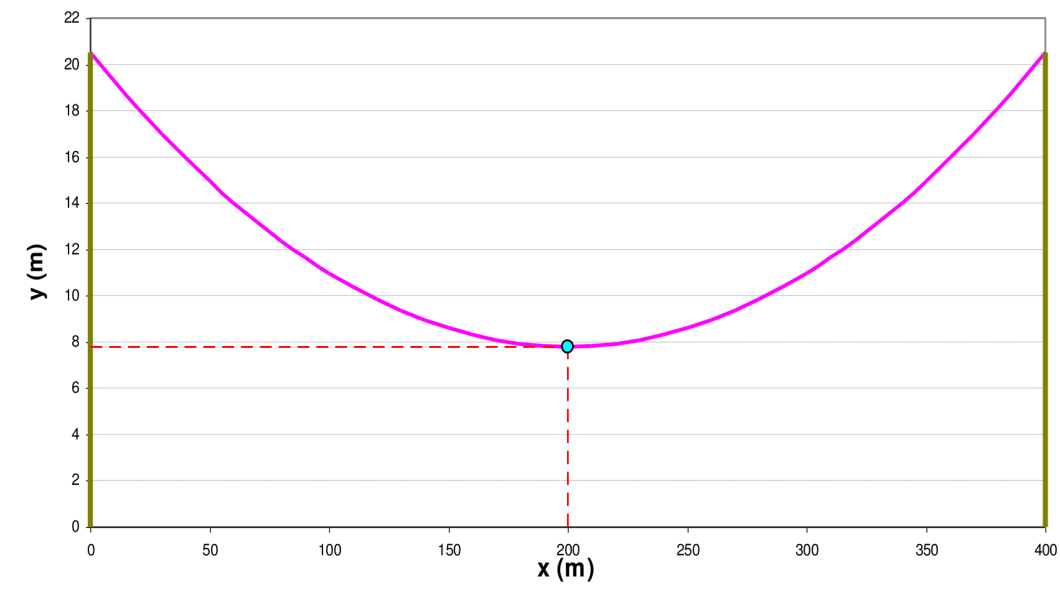

\begin{tabular}{|c|c|c|c|c|c|}
\hline $\begin{array}{l}\text { CONDUCTOR LENGTH } \\
\text { OF WHOLE SPAN }\end{array}$ & $L[\mathrm{~m}]$ & \multicolumn{2}{|c|}{$\begin{array}{c}\text { CONDUCTOR LENGTr } \\
\text { OF SPAN PART }\end{array}$} & $\begin{array}{r}L_{x 1 \times 2} \\
{[m]}\end{array}$ & $\begin{array}{c}\mathrm{L}-\mathrm{L}_{\mathrm{x} 1 \times 2} \\
{[\mathrm{~m}]}\end{array}$ \\
\hline \multirow{2}{*}{$L=\int\left[1+(d y / d x)^{2}\right]^{1 / 2} d x=$} & \multirow{2}{*}{401,07268} & $\mathrm{x}_{1}[\mathrm{~m}]$ & 100,00 & \multirow{2}{*}{200,13400} & \multirow{2}{*}{200,93868} \\
\hline & & $\mathrm{x}_{2}[\mathrm{~m}]$ & 300,00 & & \\
\hline
\end{tabular}

Fig. 3. Example 2 - Determination of the conductor length within the inclined span

\begin{tabular}{|c|c|c|}
\hline \multicolumn{3}{|c|}{ INPUT DATA } \\
\hline SPAN LENGTH & $a[\mathrm{~m}]$ & 400.00 \\
\hline $\begin{array}{c}\text { LEFT-HAND SUSPENSION } \\
\text { POINT HEIGHT }\end{array}$ & $\mathrm{h}_{1}[\mathrm{~m}]$ & 41.00 \\
\hline $\begin{array}{c}\text { RIGHT-HAND SUSPENSION } \\
\text { POINT HEIGHT }\end{array}$ & $\mathrm{h}_{2}[\mathrm{~m}]$ & 20.50 \\
\hline MAXIMAL SAG & $\mathrm{b}_{\max }[\mathrm{m}]$ & 12.70 \\
\hline
\end{tabular}

\begin{tabular}{|c|c|c|c|}
\hline \multicolumn{2}{|l|}{ VERTEX OF PARABOLA } & \multicolumn{2}{|c|}{$\begin{array}{c}\text { COEFFICIENT } \\
\text { OF PARABOLA }\end{array}$} \\
\cline { 1 - 2 } $\mathrm{X}_{\text {MIN }}[\mathrm{m}]$ & 280.709 & \multicolumn{2}{|c|}{} \\
\cline { 1 - 2 } $\mathrm{Y}_{\text {MIN }}[\mathrm{m}]$ & 15.982 & A & 0.0003175 \\
\hline
\end{tabular}

- VERTEX OF PARABOLA

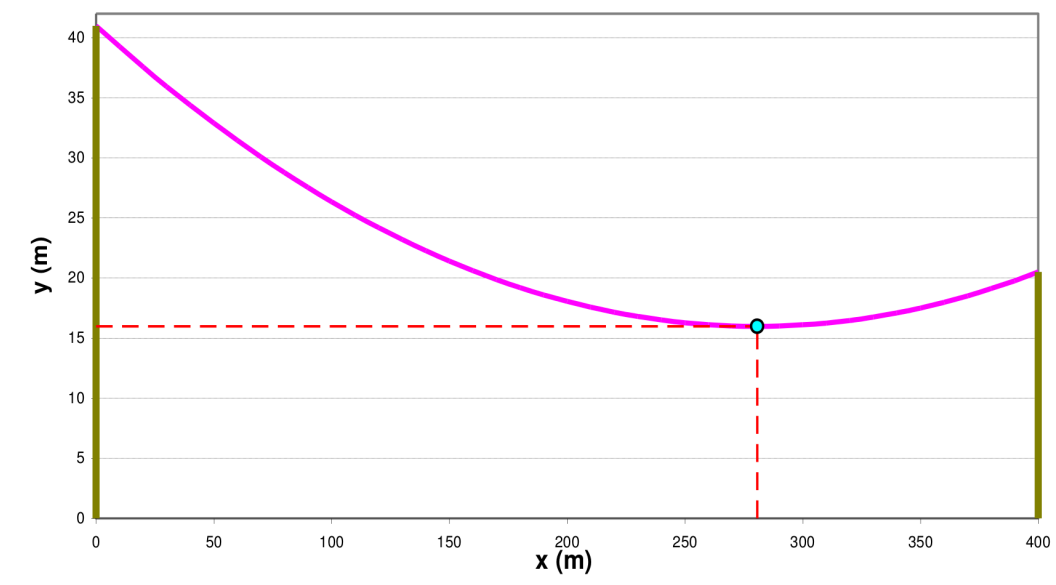

\begin{tabular}{|cc|}
\hline $\begin{array}{c}\text { CONDUCTOR LENGTH } \\
\text { OF WHOLE SPAN }\end{array}$ & $L$ [m] \\
\hline$L=\int\left[1+(\mathrm{dy} / \mathrm{dx})^{2}\right]^{1 / 2} \mathrm{dx}=$ & 401.59348 \\
\hline
\end{tabular}




\section{Conductor length of the levelled span}

The levelled span is a special case when the suspension points on two supports are on the same elevation. It is the simplest case for any kind of calculation, so for the conductor length too. The final formula is shorter than the other ones shown in this paper.

$$
\begin{aligned}
L & =\int_{-a / 2}^{a / 2} \sqrt{1+\left(y^{\prime}\right)^{2}} d x=2 \int_{0}^{a / 2} \sqrt{1+\left(y^{\prime}\right)^{2}} d x \\
& =\left.2 \frac{1}{2} \frac{a^{2}}{8 b_{\max }}\left[\operatorname{arsinh} \frac{8 b_{\max }}{a^{2}} x+\frac{8 b_{\max }}{a^{2}} x \sqrt{1+\left(\frac{8 b_{\max }}{a^{2}}\right)^{2} x^{2}}\right]\right|_{0} ^{a / 2} \\
& =\frac{a^{2}}{8 b_{\max }} \cdot\left[\operatorname{arsinh} \frac{4 b_{\max }}{a}+\frac{4 b_{\max }}{a} \sqrt{1+\left(\frac{4 b_{\max }}{a}\right)^{2}}\right]
\end{aligned}
$$

Equation (30) is the final formula for conductor length of the levelled span. The last equation has also an another form. By using identity 31]

$$
\operatorname{arsinh}(x)=\ln \left(x+\sqrt{1+x^{2}}\right)
$$

in the equation 30 , it yields

$$
\begin{aligned}
& L=\frac{a^{2}}{8 b_{\max }}\left\{\ln \left[\frac{4 b_{\max }}{a}+\sqrt{1+\left(\frac{4 b_{\max }}{a}\right)^{2}}\right]+\right. \\
& \left.+\frac{4 b_{\max }}{a} \sqrt{1+\left(\frac{4 b_{\max }}{a}\right)^{2}}\right\}
\end{aligned}
$$

Since the formula for the radius of the curvature at vertex point for the parabola [7] is given by [33]

$$
r=p=\frac{a^{2}}{8 b_{\max }}
$$

it results :

$$
L=p\left\{\ln \left[\frac{a}{2 p}+\sqrt{1+\left(\frac{a}{2 p}\right)^{2}}\right]+\frac{a}{2 p} \sqrt{1+\left(\frac{a}{2 p}\right)^{2}}\right\}
$$

\section{Practical examples}

The prepared algorithm can easily be built in Excel for solving real tasks. Two concrete examples are given in the following, one for the levelled span and the other for the inclined span.

For the given input data the conductor length within the whole span, and the conductor length within the span part have to be calculated.

The user has to write in $a, h_{1}, h_{2}, b_{\max }, x_{1}$ and $x_{2}$ input values into the programme. The $x_{\mathrm{MIN}}$ is also necessary for the length calculation, but the programme calculates it itself. On the basis of the application of the prepared algorithm the user does not have to take care about the type of span (levelled or inclined, $h_{1}<h_{2}$ or $h_{2}<h_{1}$, the lowest point is identical with vertex or not, etc.) at all. Moreover, it is not necessary to care about replacing parabola vertex into the origin. In any case the programme solves this task itself. For calculation of the conductor length within the whole span the $x_{1}=0$ and $x_{2}=a$ input values shall be given.

In the case of inclined spans the vertex of the parabola and the lowest point of the conductor are not always located at the same point, i.e. the vertex is not always the point of the conductor [5]. In that case $x_{\mathrm{MIN}}<0$ or $x_{\mathrm{MIN}}>a$, i.e. $x_{\mathrm{MIN}} \notin[0, a]$. This fact does not cause any problems for the algorithm, because in each case the necessary data for the length calculation is $x_{\text {MIN }}(x$ coordinate of vertex), but not the lowest point of the conductor. The latter is not an input data, but it is often equal with the top of the parabola (vertex point).

Since we have used the same span length and sag in both examples, the results can be compared to each other. In the example 2 (Figure 3 , inclined span with $h_{1}=2 h_{2}$ ) the conductor length is longer by 0,52 metres than it is in the example 1 (Figure 2, levelled span, $h_{1}=h_{2}$ ). The length difference is not negligible at all. But let us check the result obtained by using the formula (1).

$$
L=a+\frac{8}{3} \frac{b_{\max }^{2}}{a}=400+\frac{8}{3} \frac{12,7^{2}}{400}=401,075 \mathrm{~m}
$$

Since the formula (1) is prepared for levelled spans, the result is almost identical with the result from the example Nr. 1. The difference is only 2 millimetres, and it can be neglected. But formula (1) should not be used for inclined spans. Since the new formula is applicable in the case of levelled and inclined spans as well, its use is always recommended.

\section{Comparison of the lengths based on parabola and catenary}

Quite naturally comes the question: how big is the difference in the previous calculations when the parabola is used instead of the catenary. To answer this question, let us first determine the catenary equation from the example Nr. 1 and plot the difference between the parabola and the catenary within the span. Then we compute the catenary length and compare it to the length got by the parabola. This is the way to determine how big the length difference is due to using parabola in the given example.

Parabola equation :

$$
y_{p a r}(x)=3175 \cdot 10^{-7}(x-200)^{2}+7,8
$$

Catenary equation :

$$
y_{\text {cat }}(x)=-1569,11528+1576,91528 \cdot \cosh \frac{x-200}{1576,91528}
$$

Parabola and catenary curves from the example Nr. 1 look quite identical with each other (in Figure 4) within the span, so it is necessary to calculate the difference between them numerically, i.e. $\Delta y=y_{\text {par }}(x)-y_{\text {cat }}(x)$. The result is shown in Figure 5

Of course, the differences are zero at points $A, B$ and $C$. The biggest difference is approximately 4,3 millimetres, so it is a very small value. We have used a big sag on purpose; for a smaller sag the difference would be smaller. Since $\Delta y=y_{p a r}-$ 
$a=400 \mathrm{~m}$

$h=20,5 \mathrm{~m}$

$b_{\max }=12,7 \mathrm{~m}$

$A(0 ; h)=A(0 ; 20,5)$

$B(a ; h)=B(400 ; 20,5)$

$C\left(a / 2 ; h-b_{\max }\right)=C(200 ; 7,8)$

$y_{\text {par }}(x)=?$

$y_{\text {cat }}(x)=$ ?

$\Delta y(x)=?$

Fig. 4. Levelled span of $400 \mathrm{kV}$

Fig. 5. Difference between the heights of the parabola and the catenary in the example 1.
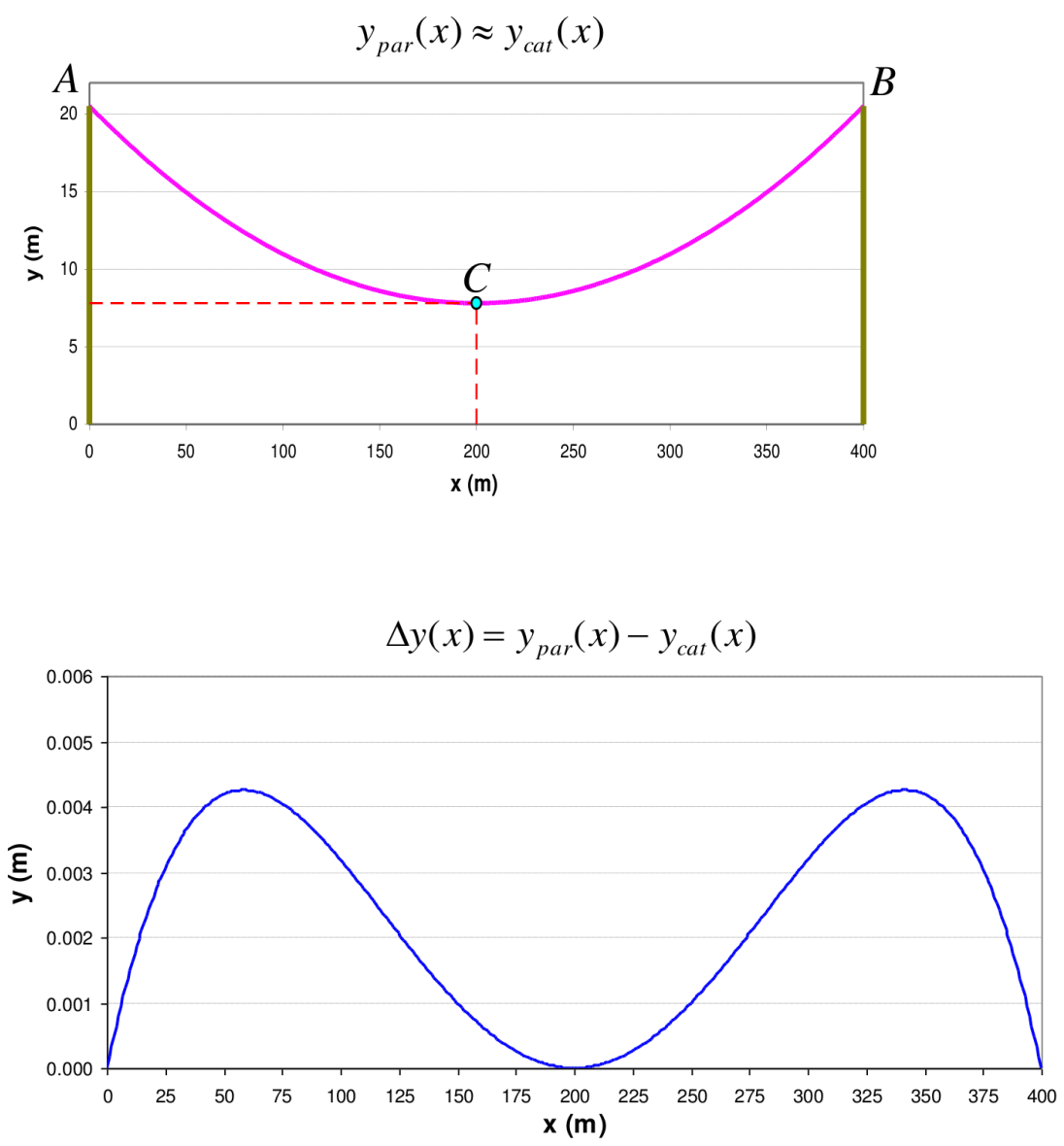

$y_{\text {cat }} \geq 0 \Rightarrow L_{\text {par }}<L_{c a t}$ within the interval $[0, a]$. The final task is to calculate $\Delta L=L_{c a t}-L_{\text {par }}$. That will be the difference between the length calculation using parabola and catenary curve. Since $L_{p a r}$ is already calculated ( $L_{p a r}=401,07268 \mathrm{~m}$ ), we only have to calculate $L_{c a t}$. In the case of the example $\mathrm{Nr}$. 1 , the formula 37) can be used [8,9]:

$$
L_{c a t}=2 c \cdot \sinh \frac{a}{2 c}
$$

From the equation (36) the constant of the catenary is $c=$ 1576,91528 . Since $a=400 \mathrm{~m}$, the length of the catenary is $L_{c a t}=401,07325 \mathrm{~m}$ and $\Delta L=L_{c a t}-L_{p a r}=0,57 \mathrm{~mm}$. So in the case of the example Nr.1 (in Figure 2, levelled span with a big sag) the length difference is negligible.

In the case of the example Nr. 2 (in Figure 3 , inclined span with a big sag) the difference between the lengths got by the parabola and by the catenary could be a few centimetres and $\Delta L$ could be a few millimetres. So the conductor curve can be freely considered as a parabola for spans up to 400 metres.

The calculations and conclusions presented in this section relate to the special case, when the conductor sag $b_{\max }$ is assumed to be identical, both of parabolic and catenary methods are used.

\section{Conclusions}

As it can be seen in the examples, the final algorithm makes it possible to determine not only the conductor length within the whole span, but the length between any two points of the conductor within the span, i.e. the conductor length of any span part. The algorithm is applicable in the case of levelled and inclined spans as well. So it is a concrete solution useful for conventional tasks and also for some special tasks. The presented examples prove the simplicity of the algorithm in real applications. It is partly due to the fact that the origin is put to the bottom of the left-hand side support; this is an unusual approach in comparison to existing scientific literature for similar topics. The subproducts of the algorithm are the vertex point coordinates $x_{\mathrm{MIN}}$ and $y_{\mathrm{MIN}}$. When $x_{\mathrm{MIN}} \in[0, a]$, these are the coordinates of the lowest point of the conductor at the same time. The lowest point is one characteristic point of the inclined span, but very often the most critical point, too. Furthermore, the algorithm defines the parabola coefficient $A$, so it is easy to determine the equation of the conductor height in vertex form of the parabola in any concrete case of the tasks. With the help of the shown algorithm the conductor curve and the lowest point are not difficult tasks at all.

Finally, it is shown that for the inclined span the conductor length differs significantly from that of the levelled span having the same span length and sag. This shows the importance of the new formula, meanwhile the existing formula (1) is applicable only for the levelled spans. The application of the new formula is recommended up to 400 metres.

With a simple numerical solution (successive approximation 
method) the limitation mentioned in the paper for the equations (which is in fact correct that the sag must be known) could easily be by-passed resulting in inverse function when the conductor length is given and the sag is calculated - without the need for new equations.

\section{References}

1 Pansini A, Electrical Distribution Engineering, The Fairmont Press, Inc., 2007.

2 Stewart J, Single Variable Calculus, CENGAGE Learning, 2011.

3 Gustafson D, Frisk P, Hughes J, College Algebra, CENGAGE Learning, 2010.

4 Hatibovic A, Mathematical calculation of the parabola wire and sag for spans up to 400 meters, Bosanskohercegovacka elektrotehnika, 5, (2012).

5 Hatibovic A, A vezeték legmélyebb pontjának meghatározása, MEE 58. Vándorgyúlés, (2011).

6 Hatibovic A, Tomic M, Determination of the lowest point of conductor for inclined spans, CIGRÉ conference, (2011).

7 Perneczky G, Szabadvezetékek feszítése, Múszaki Könyvkiadó; Budapest, 1968.

8 Grigsby LL, Electric Power Engineering Handbook, Taylor \& Francis Group, LLC, 2006.

9 CIGRÉ 324, Sag-tension calculation methods for overhead lines, 2007. 